Article

\title{
Lignans from Machilus thunbergii as Thymic Stromal Lymphopoietin Inhibitors
}

\author{
Hyeji Shin ${ }^{\dagger}$, Yoo Kyong Han ${ }^{\dagger}$, Youngjoo Byun, Young Ho Jeon and Ki Yong Lee *(D) \\ College of Pharmacy, Korea University, Sejong 30019, Korea; hjshin90@korea.ac.kr (H.S.); \\ kkoo_@naver.com (Y.K.H.); yjbyun1@korea.ac.kr (Y.B.); yhjeon@korea.ac.kr (Y.H.J.) \\ * Correspondence: kylee11@korea.ac.kr; Tel.: +82-44-860-1623 \\ + These authors contributed equally to this work.
}

Citation: Shin, H.; Han, Y.K.; Byun, Y.; Jeon, Y.H.; Lee, K.Y. Lignans from Machilus thunbergii as Thymic Stromal Lymphopoietin Inhibitors. Molecules 2021, 26, 4804. https://doi.org/ $10.3390 /$ molecules26164804

Academic Editor: David Barker

Received: 5 July 2021

Accepted: 6 August 2021

Published: 8 August 2021

Publisher's Note: MDPI stays neutral with regard to jurisdictional claims in published maps and institutional affiliations.

Copyright: (c) 2021 by the authors. Licensee MDPI, Basel, Switzerland. This article is an open access article distributed under the terms and conditions of the Creative Commons Attribution (CC BY) license (https:// creativecommons.org/licenses/by/ $4.0 /)$.

\begin{abstract}
Thymic stromal lymphopoietin (TSLP) plays an important role in the pathophysiology of various allergic diseases that are mediated by $\mathrm{T}$ helper cell type-2 (Th2) responses, including asthma and atopic dermatitis. The primary focus of this study was the identification of potent inhibitors of the TSLP signaling pathway for potential therapeutic use. The $80 \%$ methanol extract of Machilus thunbergii bark significantly inhibited the signal transducer and activator of transcription 5 (STAT5) phosphorylation in human mast cell (HMC)-1 cells. Through activity-guided isolation, three lignans (1-3) were obtained and identified as (+)-galbelgin (1), meso-dihydroguaiaretic acid (2), and machilin A (3). Among them, two lignans (1 and 2) significantly inhibited STAT5 phosphorylation and TSLP/TSLPR interaction, as determined by ELISA. Our results indicated that lignans isolated from $M$. thunbergii are a promising resource for the treatment of allergic diseases.
\end{abstract}

Keywords: Machilus thunbergii; TSLP; STAT5; allergic disease; lignan

\section{Introduction}

The prevalence of allergic diseases, such as asthma, rhinitis, and atopic dermatitis, is rapidly increasing due to continuous antigen exposure caused by changes in the environment, industrialization, and pollution. Thymic stromal lymphopoietin (TSLP), an epithelial cell-derived cytokine, plays a key role in allergic diseases promoted by dendritic cell-mediated T helper cell type-2 (Th2) [1-3]. When exposed to allergens, epithelial cells stimulate the production of cytokines, such as TSLP, interleukin-25 (IL-25), and IL-33. TSLP binds to the heterodimeric receptor complex of TSLP receptor (TSLPR) subunit and interleukin-7 receptor $\alpha$ chain (IL-7R $\alpha$ ). The binding induces the phosphorylation and activation of Janus kinases (JAKs) and the signal transducers and activators of transcription 5 (STAT5), leading to an allergic response as a result of the overproduction of Th2 cells $[1,4,5]$. Hence, TSLP signaling inhibitors can be used as materials for the development of allergy drugs. Common allergy drugs (antihistamines, steroids, and immunosuppressants) are useful only for symptomatic treatment and have side effects that include vomiting, headache, and dizziness when taken over a long period of time [6,7]. In addition, allergic diseases may continuously develop and reappear throughout life, with frequent recurrences and exacerbations affecting the quality of life [7,8]. Therefore, there is a need to develop a safe treatment that can be used for long periods of time, as well as being a fundamental treatment. Natural products capable of synergic effects due to the diversity of chemical structures have been suggested as alternatives to allergy drugs [9].

Machilus thunbergii (M. thunbergii) Sieb. et Zucc. (Lauraceae) is an evergreen broadleaved tree up to $20 \mathrm{~m}$ tall, and its bark is dark brown with gray markings. It grows mainly in broad-leaved forests below $800 \mathrm{~m}$ and is distributed in warm regions such as Korea, China, Japan, and Taiwan $[10,11]$. The bark of $M$. thunbergia has been used in folk medicine for the treatment of abdominal pain and distension, leg edema, and antiinflammatory responses $[10,12]$. Its bark consists of lignans (machilin A-I, licarlin A and B, 
and meso-dihydroguaiaretic acid), flavonoids (kaempferol, quercetin, and taxifolin), and butanolides (obtusilactone B, linderanolide, litsenolide A2, B1, and B2) [13-17], which have been reported to exert hepatoprotective [18], neuroprotective [19,20], antibacterial [21], and anticancer activities [22].

Seo et al. investigated the antiallergic effect of $M$. thunbergii extracts in vitro and found that the extracts of the whole plant, leaf, root, stem, fruit, and flower of $M$. thunbergii significantly inhibit the secretion of immunoglobulin (Ig) E in U266 cells [23]. In a previous study, an $80 \%$ methanol extract of the bark of $M$. thunbergii Sieb. et Zucc. significantly inhibited STAT5 phosphorylation in human mast cell (HMC)-1 cells. However, to the best of our knowledge, researchers have yet to investigate whether a direct correlation exists between the chemical composition and antiallergic activity of $M$. thunbergii. Therefore, the main objective of this study was to isolate and analyze antiallergic active constituents from the bark of $M$. thunbergii.

\section{Results and Discussion}

In a study to identify antiallergic active constituents from natural products, $80 \% \mathrm{MeOH}$ extracts of the bark of $M$. thunbergii exhibited significant TSLP inhibitory activity in the pSTAT5 assay $(69.2 \%$ at $100 \mu \mathrm{g} / \mathrm{mL}$; Table 1$)$. In an attempt to evaluate active constituents obtained from the bark of $M$. thunbergii, three lignans were isolated and identified as (+)galbelgin (1) [24,25], meso-dihydroguaiaretic acid (2) [26,27], and machilin A (3) [28,29], by ${ }^{1} \mathrm{H}-\mathrm{NMR},{ }^{13} \mathrm{C}-\mathrm{NMR}$, and MS spectral data and compared them with previously reported physical and spectroscopic data (Figure 1).

Table 1. The effect of isolated compounds on STAT5 phosphorylation by flow cytometry.

\begin{tabular}{ccc}
\hline & \multicolumn{2}{c}{ STAT5 Phosphorylation (\%) } \\
\cline { 2 - 3 } & $\mathbf{3 \mu \mathbf { M }}$ & $\mathbf{3 0 \mu \mathbf { M }}$ \\
\hline Extracts of $\boldsymbol{M}$. thunbergii & $79.2^{(\mathrm{a})}$ & $69.2^{(\mathrm{b})}$ \\
$\mathbf{1}$ & 67.6 & 54.5 \\
$\mathbf{2}$ & 68.7 & 64.1 \\
$\mathbf{3}$ & 111.9 & 104.3 \\
\hline
\end{tabular}

(a) $50 \mu \mathrm{g} / \mathrm{mL}$; $^{\text {(b) }} 100 \mu \mathrm{g} / \mathrm{mL}$.<smiles>COc1ccc([C@H]2O[C@@H](c3ccc(OC)c(OC)c3)[C@H](C)[C@H]2C)cc1OC</smiles>

1

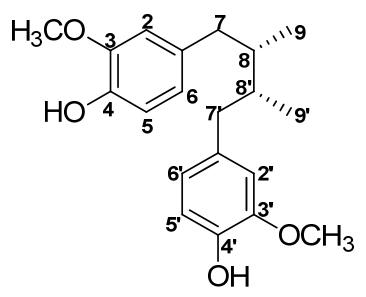

2

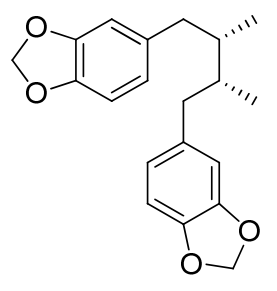

3

Figure 1. Chemical structures of isolated compounds 1-3 of Machilus thunbergii (M. thunbergii).

In order to evaluate the antiallergic activity of compounds 1-3 of the bark of M. thunbergii, an assay was performed to confirm the inhibitory effect of STAT5 phosphorylation and binding between TSLP and TSLPR through pSTAT5 assay and ELISA assay, respectively. TSLP, a cytokine involved in the initiation of allergic reactions, has been reported as the only cytokine that characteristically phosphorylates STAT5 among STAT proteins using a combination of JAK1 and JAK2 linked to the IL-7R $\alpha$ and TSLPR [30].

Compounds 1 and 2 showed strong pSTAT5 inhibitory activities of 54.5\% and 64.1\% at $30 \mu \mathrm{M}$, respectively, in HMC-1 cells stimulated with hTSLP (Table 1 and Figure S1). None of them have reported pSTAT5 inhibitory activity. Song et al. investigated the antiasthmatic activity of meso-dihydroguaiaretic acid (2) in an ovalbumin (OVA)-induced allergic asthma model and found that it decreased the levels of Th2-type cytokines and total immunoglobulin (Ig) E [31]; however, the antiallergic activity of (+)-galbelgin (1) was 
first identified in our study. In addition, as shown in Table 2, compound 1 showed more than $20 \%$ inhibitory activity of hTSLP-hTSLPR interaction at $0.3 \mathrm{mM}$, which correlated with the pSTAT5 assay. However, the other two compounds ( 2 and 3 ) did not show more than $20 \%$ inhibitory activity at $0.3 \mathrm{mM}$. These results suggested compound $\mathbf{1}$ as a material that can fundamentally prevent and treat allergic diseases by inhibiting TSLP-mediated signal transduction.

Table 2. The inhibitory effects of isolated compounds 1-3 on thymic stromal lymphopoietin (TSLP)/TSLP receptor (TSLPR) interaction by ELISA.

\begin{tabular}{ccc}
\hline \multirow{2}{*}{ Compounds } & \multicolumn{2}{c}{ hTSLP/hTSLPR Interaction Inhibition (\%) } \\
\cline { 2 - 3 } & $\mathbf{0 . 1} \mathbf{~ \mathbf { M }}$ & $\mathbf{0 . 3} \mathbf{~ m M}$ \\
\hline Control & & $0.0 \pm 0.9$ \\
$\mathbf{1}$ & $17.2 \pm 2.2^{* *}$ & \\
$\mathbf{2}$ & $13.8 \pm 0.6^{* *}$ & $16.7 \pm 1.9^{*}$ \\
$\mathbf{3}$ & $11.0 \pm 1.5^{* *}$ & $19.5 \pm 1.2^{*}$ \\
\hline
\end{tabular}

a Samples that differ significantly from the control. ${ }^{*} p<0.05,{ }^{* *} p<0.01$.

To further elucidate the inhibitory activity of the isolated compounds against hTSLPhTSLPR interaction, molecular docking studies were conducted for human TSLP in complex with TSLPR and IL-7R $\alpha$. As shown in Table 3, compound 1 had the highest docking score compared to the other compounds, which is consistent with the ELISA results. Moreover, as shown in Figure 2A, compound $\mathbf{1}$ appeared to be bound to the hTSLP-hTSLPR interaction interface. The interaction mode of compound $\mathbf{1}$ is shown in Figure 2B. Six hydrogen bonds were formed between the $3^{\prime}, 4,3$, and 4"-methoxy oxygen and 1-oxygen of compound 1 with Lys161, Lys188, Gln164, and Glu191, respectively. The lengths of these hydrogen bonds were $1.89,1.88,2.46,2.13,2.13$, and $2.43 \AA$. As shown in Figure $2 \mathrm{C}, \mathrm{D}$, six hydrogen bonds were formed between 3, 3'-methoxyl oxygen and 4, 4'-OH and Gln164, Glu165, Asp192, Glu191, and Ser184, with lengths of 1.91, 1.93, 2.07, 2.09, 3.05, and $2.95 \AA$, respectively. On the other hand, compound 3 formed four hydrogen bonds between methylenedioxy oxygen atoms and Ser162, Glu149, and Lys188, with lengths of 1.93, 2.08, 2.56, and $2.95 \AA$, respectively (Figure 2E,F). These results demonstrate that these compounds are able to bind tightly to catalytic amino acid residues to inhibit hTSLP-hTSLPR interaction. Furthermore, compounds with more hydroxyl and methoxy groups exhibited more hydrogen bonding and higher docking scores. As a high-scoring inhibitor of the hTSLP-hTSLPR interaction, compound $\mathbf{1}$ is a good candidate for the treatment of allergic diseases, consistent with the ELISA results.

Table 3. Molecular docking results of isolated compounds 1-3 on TSLP/TSLPR interaction.

\begin{tabular}{ccc}
\hline Compounds & $\begin{array}{c}\text { Docking Analysis } \\
\text { (Total Score) }^{\mathbf{a}}\end{array}$ & Key Residues \\
\hline $\mathbf{1}$ & 7.4243 & Lys161(1.89), Lys188(1.88, 2.46), Gln164(2.13), and \\
& & Glu191(2.13, 2.43) \\
$\mathbf{2}$ & 7.2410 & $\mathrm{Gln} 164(1.91)$, Glu165(1.93), Asp192(2.07), \\
$\mathbf{3}$ & 5.7852 & Glu191(2.09, 3.05), and Ser184(2.95) \\
\end{tabular}

a Total scores were expressed in $-\log 10\left(K_{d}\right)^{2}$ units to represent binding affinities. 
(A)

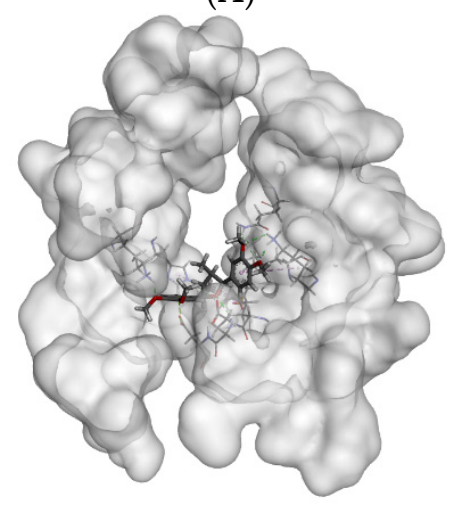

(C)

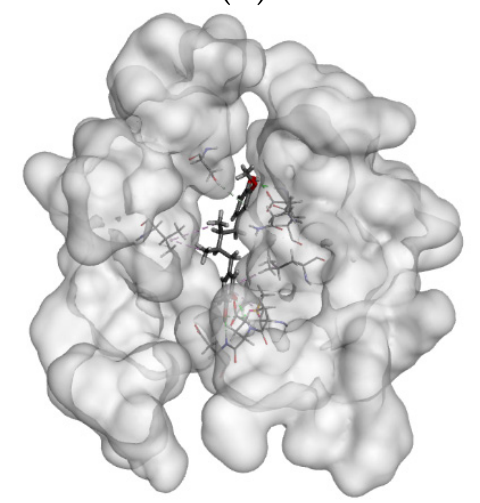

(E)

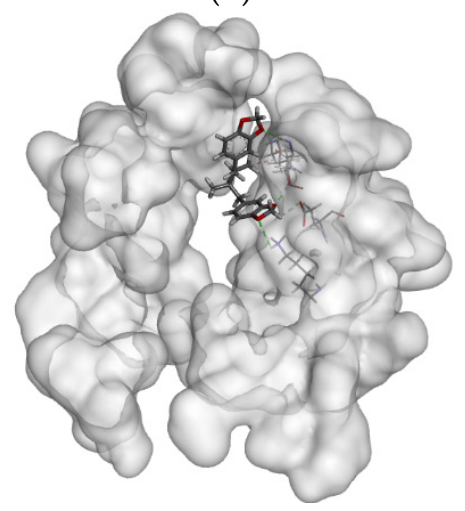

(B)

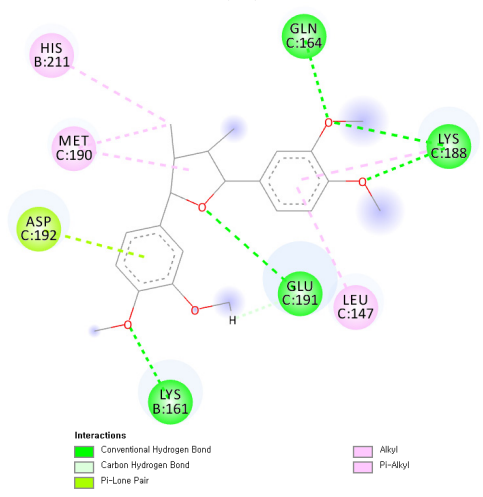

(D)

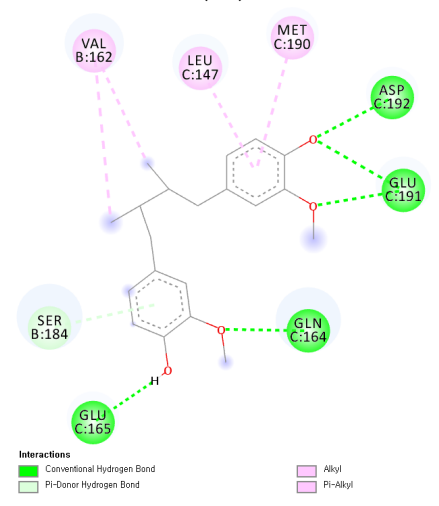

(F)

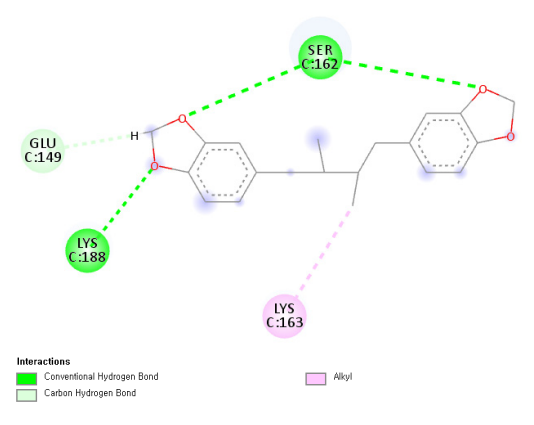

Figure 2. Molecular docking results of isolated compounds 1-3 against human TSLP in complex with TSLPR and interleukin-7 receptor $\alpha$ chain (IL-7R $\alpha$ ): (A) three-dimensional (3D) docking image of compound 1; (B) two-dimensional (2D) docking image of compound 1; (C) 3D docking image of compound 2; (D) 2D image picture of compound 2; (E) 3D docking image of compound 3; (F) 2D docking picture of compound 3.

\section{Materials and Methods}

\subsection{General Experimental Procedures}

Intracellular phospho-STAT5 (pSTAT5) was measured using a BD LSR Fortessa Flow cytometer (BD Biosciences, San Diego, CA, USA). NMR spectra were recorded on a Bruker SPECTROSPIN $300 \mathrm{MHz}$ spectrometer (Bruker Corporation, Billerica, MA, USA). For the pSTAT5 assay measuring TSLP inhibitory activity, recombinant human TSLP was purchased from R\&D Systems (Minneapolis, MN, USA) and BD Cytofix/Cytoperm and Alexa Fluor 647 mouse anti-STAT5 (pY694) were purchased from BD Biosciences (San Diego, CA, USA). For the ELISA assay to assess hTSLP-hTSLPR interaction, Ni-NTA HisSorb plates were purchased from Qiagen (Hilden, Germany), and monoclonal anti-FLAG antibody conjugated to HRP and o-phenylenediamine dihydrochloride were purchased from Sigma- 
Aldrich Co. (St. Louis, MO, USA). Iscove's modified Dulbecco's medium (IMDM) and fetal bovine serum (FBS) were purchased from Hyclone Laboratories Inc. (Logan, UT, USA). Penicillin-streptomycin was purchased from Gibco Industries Inc. (Auckland, NZ, USA).

\subsection{Plant Material}

The bark of $M$. thunbergii was obtained from the Medicinal Herb Garden, College of Pharmacy, Seoul National University, Seoul, Korea, and identified by Dr. Ki Yong Lee, a professor at the College of Pharmacy, Korea University (Sejong, Korea). The voucher specimen (KUP-HD066) was deposited at the Laboratory of Pharmacognosy, College of Pharmacy, Korea University.

\subsection{Extraction and Isolation}

The bark of $M$. thunbergii (500 g) was extracted three times with $80 \% \mathrm{MeOH}$ under ultrasonic conditions for $90 \mathrm{~min}$. After removing the solvent in vacuo, the obtained crude extracts $(45.2 \mathrm{~g})$ were suspended in distilled water and partitioned using dichloromethane to yield a dichloromethane fraction $(7.1 \mathrm{~g})$. The dichloromethane fraction was subjected to medium-pressure liquid chromatography (MPLC) on a silica gel column using an Isolera One system (Biotage, Uppsala, Sweden) and eluted with an $n$-hexane:EtOAc:MeOH gradient (20:1:0 $\rightarrow 0: 0: 1)$ to yield 32 fractions (D1-D32). Compound $\mathbf{1}(2.3 \mathrm{mg})$ was purified from D20 via recrystallization. Fractions D5 and D7 were separated using Sephadex LH-20 column chromatography. Compounds $2(12.3 \mathrm{mg})$ and $3(2.1 \mathrm{mg})$ were obtained from D7-2 and D5-4, respectively, and were observed as a single spot on a TLC plate.

\section{4. pSATA5 Assay}

\subsubsection{Cell Culture}

HMC-1 cells were obtained from the Department of Food Technology and Inflammatory Disease Research Center, Hoseo University, Asan, Chungnam, Korea. HMC-1 cells were cultured in IMDM containing $10 \%$ FBS and $1 \%$ penicillin-streptomycin at $37^{\circ} \mathrm{C}$ under a humidified atmosphere of $5 \% \mathrm{CO}_{2}$ and $95 \%$ air. Subculturing was performed every 2 days. When HMC- 1 cells were grown to $80 \%$ confluence, the cells were harvested and centrifuged at $1000 \mathrm{rpm}$ for $3 \mathrm{~min}$. Then, the cells were recultured with a complete growth medium in a 1:3 volume ratio.

\subsubsection{Flow Cytometry}

pSTAT5 staining was performed according to the protocol obtained from the laboratory of Susan Kaech, Department of Immunobiology, Yale University School of Medicine, New Haven, CT, USA. Briefly, HMC- 1 cells were seeded at a density of $1 \times 10^{7}$ cells $/ \mathrm{mL}$ in a 96-well U-bottom plate, and the supernatant was discarded after centrifugation (1650 rpm for $2 \mathrm{~min}$ ). The cells were then stimulated with $100 \mathrm{ng} / \mathrm{mL}$ of recombinant hTSLP alone (control) or with the sample for $30 \mathrm{~min}$ and fixed in the BD Cytofix/Cytoperm solution for $10 \mathrm{~min}$. The fixed cells were permeabilized in ice-cold methanol for $30 \mathrm{~min}$. After permeabilization, intracellular pSTAT5 was stained with Alexa Fluor 647 mouse antiSTAT5 for $30 \mathrm{~min}$. The stained cells were washed twice in FACS buffer and resuspended in the FACS buffer before flow cytometry analysis. pSTAT5 was acquired on a BD LSRFortessa flow cytometer and analyzed using FlowJo software (version 9.7.6) (Tree Star Inc., Ashland, OR, USA).

\subsection{ELISA Assay}

ELISA was performed according to a previously described method [4]. The C-terminal octa-histidine tag (TSLPR-His) and N-terminal FLAG tag (FLAG-hTSLP) were obtained from Dr. Young Ho Jeon, a professor at the College of Pharmacy, Korea University, Sejong, Korea. A solution containing hTSLPR with C-terminal octa-histidine tag (TSLPR-His) was added to each well at a rate of $100 \mu \mathrm{L}$. After incubation at a room temperature for $2 \mathrm{~h}$, the plate was washed three times with $200 \mu \mathrm{L}$ of PBS containing $0.05 \%$ Tween-20 to 
remove unbound TSPL-His. Potential inhibitors were treated with concentrations of 0.3 and $0.1 \mathrm{mM}$, and $100 \mu \mathrm{L}$ of TSLP with N-terminal FLAG tag (FLAG-hTSLP) was added and incubated overnight $(18 \mathrm{~h})$ at $4{ }^{\circ} \mathrm{C}$. The plate was washed three times to remove unbound FLAG-hTSLP. Next, the plate was blocked with the $100 \mu \mathrm{L}$ blocking buffer (PBS with 0.05\% Tween-20, 1\% non-fat dry milk, and 1\% bovine serum albumin) for $2 \mathrm{~h}$ and washed three times. Then, the plate was coated with $100 \mu \mathrm{L}$ of monoclonal anti-FLAG antibody conjugated to HRP and incubated for $2 \mathrm{~h}$. The incubated plate was washed five times, and $200 \mu \mathrm{L}$ of an $o$-phenylenediamine dihydrochloride solution were added and incubated for $30 \mathrm{~min}$. To stop the reaction, $1 \mathrm{~N} \mathrm{HCl}$ was added to the plate, and the inhibitory effect was determined by measuring the optical density (OD) at $450 \mathrm{~nm}$ in a 96 -well microplate reader. The inhibitory effects were calculated using the following equation:

$$
\text { Inhibitory effect }(\%)=(1-\text { OD of sample } / O D \text { of control }) \times 100 \% \text {. }
$$

\subsection{Molecular Docking Studies}

Molecular docking studies were conducted using SYBYL-X (version 2.1.1) (Tripos Ltd. St. Louis, MO, USA). The structure of human TSLP in complex with TSLPR and IL-7Ralpha (PDB-ID: 5J11) was provided by the Research Collaboratory for Structural Bioinformatics Protein Data Bank (RCSB PDB). The protein was prepared with a Tripos force field and a termination of 0.05 , and all water compounds were removed. The three-dimensional (3D) structures of the ligands were prepared using Chem3D Pro and saved as mol files. Molecular docking was performed using the Surflex preparation protocol in SYBYL-X 2.1.1, and the docking results were analyzed by Discovery Studio 2019 Client (Biovia Co., San Diego, CA, USA), which showed the interaction between ligands and residues in a docked complex.

\section{Conclusions}

The antiallergic activity of lignans isolated from the bark of $M$. thunbergii was evaluated. Among these, (+)-galbelgin (1) and meso-dihydroguaiaretic acid (2) were found to exhibit strong pSTAT5 and TSLP/TSLPR interaction inhibitory activity in an in vitro assay (STAT5 assay and ELISA assay) and an in silico assay (docking study). Notably, (+)-galbelgin (1), the most bioactive compound, was identified as an antiallergic agent for the first time in this study. Therefore, lignans of the bark of $M$. thunbergii may be a good resource for the development of antiallergic agents targeting the TSLP signaling pathway.

Supplementary Materials: The following are available, Figure S1: Flow cytometric analysis of STAT5 phosphorylation levels in hTSLP-stimulated HMC-1 cells.

Author Contributions: Conceptualization, Y.H.J. and K.Y.L.; methodology, H.S., Y.K.H. and K.Y.L.; software, H.S. and Y.K.H.; validation, H.S. and Y.K.H.; formal analysis, Y.K.H. and H.S.; investigation H.S., Y.K.H. and K.Y.L.; data curation, Y.B., Y.H.J. and K.Y.L.; writing—original draft preparation, H.S., Y.K.H. and K.Y.L.; writing-review and editing, H.S. and K.Y.L.; supervision, Y.B., Y.H.J. and K.Y.L. All authors have read and agreed to the published version of the manuscript.

Funding: This research was supported by a National Research Foundation of Korea grant funded by the Korean Government (NRF-2014R1A4A1007304 and 2019R1A6A1A03031807).

Conflicts of Interest: The authors declare no conflict of interest.

Sample Availability: Samples of the compounds are not available from the authors.

\section{References}

1. Adamu, R.M.; Malik, B.K. Molecular Modeling and Docking Assessment of Thymic Stromal Lymphopoietin for the Development of Natural Anti Allergic Drugs. J. Young. Pharm. 2018, 10, 178-182. [CrossRef]

2. Han, N.R.; Moon, P.D.; Kim, H.M.; Jeong, H.J. Tryptanthrin ameliorates atopic dermatitis through down-regulation of TSLP. Arch Biochem. Biophys. 2014, 542, 14-20. [CrossRef]

3. Moon, P.D.; Jeong, H.J.; Kim, H.M. Effects of schizandrin on the expression of thymic stromal lymphopoietin in human mast cell line HMC-1. Life Sci. 2012, 91, 384-388. [CrossRef] 
4. Park, B.B.; Choi, J.W.; Park, D.; Choi, D.; Paek, J.; Kim, H.J.; Son, S.Y.; Mushtaq, A.U.; Shin, H.; Kim, S.H.; et al. Structure-activity relationships of baicalein and its analogs as novel TSLP inhibitors. Sci. Rep. 2019, 9, 8762. [CrossRef] [PubMed]

5. Zhong, J.; Sharma, J.; Raju, R.; Palapetta, S.M.; Prasad, T.S.; Huang, T.C.; Yoda, A.; Tyner, J.W.; van Bodegom, D.; Weinstock, D.M.; et al. TSLP signaling pathway map: A platform for analysis of TSLP-mediated signaling. Database 2014, 2014, 1-8. [CrossRef]

6. Bantz, S.K.; Zhu, Z.; Zheng, T. The Atopic March: Progression from Atopic Dermatitis to Allergic Rhinitis and Asthma. J. Clin. Cell Immunol. 2014, 5, 202. [CrossRef] [PubMed]

7. Spergel, J.M. From atopic dermatitis to asthma:the atopic march. Ann. Allergy Asthma Immunol. 2010, 105, 99-106. [CrossRef]

8. Kapoor, Y.; Kumar, K. Structural and clinical impact of anti-allergy agents: An overview. Bioorg. Chem. 2020, 94, 103351. [CrossRef] [PubMed]

9. Smruti, P. A review on natural remedies used for the treatment of respiratory disorders. Int. J. Pharm. 2021, 8, 104-111. [CrossRef]

10. Wu, S.-J.; Len, W.-B.; Huang, C.-Y.; Liou, C.-J.; Huang, W.-C.; Lin, C.-F. Machilus thunbergii extract inhibits inflammatory response in lipopolysaccharide-induced RAW264.7 murine macrophages via suppression of NF- $\mathrm{B}$ and p38 MAPK activation. Turk. J. Biol. 2015, 39, 657-665. [CrossRef]

11. Ren, Q.; Wu, D.; Wu, C.; Wang, Z.; Jiao, J.; Jiang, B.; Zhu, J.; Huang, Y.; Li, T.; Yuan, W. Modeling the Potential Distribution of Machilus thunbergii under the Climate Change Patterns in China. Open J. For. 2020, 10, 217-231. [CrossRef]

12. Ma, C.J.; Kim, Y.C.; Sung, S.H. Compounds with neuroprotective activity from the medicinal plant Machilus thunbergii. J. Enzym. Inhib. Med. Chem. 2009, 24, 1117-1121. [CrossRef]

13. Jeon, J.S.; Oh, S.J.; Lee, J.Y.; Ryu, C.S.; Kim, Y.M.; Lee, B.H.; Kim, S.K. Metabolic characterization of meso-dihydroguaiaretic acid in liver microsomes and in mice. Food Chem. Toxicol. 2015, 76, 94-102. [CrossRef] [PubMed]

14. Kim, W.; Lyu, H.N.; Kwon, H.S.; Kim, Y.S.; Lee, K.H.; Kim, D.Y.; Chakraborty, G.; Choi, K.Y.; Yoon, H.S.; Kim, K.T. Obtusilactone B from Machilus thunbergii targets barrier-to-autointegration factor to treat cancer. Mol. Pharm. 2013, 83, 367-376. [CrossRef] [PubMed]

15. Lee, M.K.; Yang, H.; Ma, C.J.; Kim, Y.C. Stimulatory activity of lignans from Machilus thunbergii on osteoblast differentiation. Biol. Pharm. Bull. 2007, 30, 814-817. [CrossRef] [PubMed]

16. Ma, C.J.; Kim, S.R.; Kim, J.; Kim, Y.C. Meso-dihydroguaiaretic acid and licarin A of Machilus thunbergii protect against glutamateinduced toxicity in primary cultures of a rat cortical cells. Br. J. Pharm. 2005, 146, 752-759. [CrossRef]

17. Karikome, H.; Mimaki, Y.; Sashida, Y. A butanolide and phenolics from Machilus thunbergii. Phytochemistry 1991, 30, 315-319. [CrossRef]

18. Yu, Y.U.; Kang, S.Y.; Park, H.Y.; Sung, S.H.; Lee, E.J.; Kim, S.Y.; Kim, Y.C. Antioxidant Lignans from Machilus thunbergii protect CCl4-injured primary cultures of rat hepatocytes. J. Pharm. Pharm. 2000, 52, 1163-1169. [CrossRef]

19. Ma, C.J.; Lee, M.K.; Kim, Y.C. Meso-dihydroguaiaretic acid attenuates the neurotoxic effect of staurosporine in primary rat cortical cultures. Neuropharmacology 2006, 50, 733-740. [CrossRef]

20. Ma, C.J.; Sung, S.H.; Kim, Y.C. New neuroprotective dibenzyl butane lignans isolated from Machilus thunbergii. Nat. Prod. Res. 2010, 24, 562-568. [CrossRef]

21. Favela-Hernandez, J.M.; Garcia, A.; Garza-Gonzalez, E.; Rivas-Galindo, V.M.; Camacho-Corona, M.R. Antibacterial and antimycobacterial lignans and flavonoids from Larrea tridentata. Phytother. Res. 2012, 26, 1957-1960. [CrossRef]

22. Le, T.V.T.; Nguyen, P.H.; Choi, H.S.; Yang, J.-L.; Kang, K.W.; Ahn, S.-G.; Oh, W.K. Diarylbutane-type lignans from Myristica fragrans (Nutmeg) show the cytotoxicity against breast cancer cells through activation of AMP-activated protein kinase. Nat. Prod. Sci. 2017, 23, 21-28. [CrossRef]

23. Seo, S.G.; Park, D.J.; Cho, H.S.; Kim, G.N.; Kim, J.H.; Park, J.H.; Jin, M.H. Compositions Containing Paper Mulberry Extracts. Patent WO2021137678A1, 30 June 2021.

24. Liu, J.-S.; Huang, M.-F.; Gao, Y.-L. The structure of chicanine, a new lignan from Schisandra sp. Can. J. Chem. 1981, 59, 1680-1684. [CrossRef]

25. Rye, C.E.; Barker, D. Asymmetric synthesis of (+)-galbelgin, (-)-kadangustin J, (-)-cyclogalgravin and (-)-pycnanthulignenes A and B, three structurally distinct lignan classes, using a common chiral precursor. J. Org. Chem. 2011, 76, 6636-6648. [CrossRef]

26. Nakatani, N.; Ikeda, K.; Kikuzaki, H.; Kido, M.; Yamaguchi, Y. Diaryldimethylbutane Lignans from Myristica argentea and their antimicrobial action against Streptococcus mutans. Phytochemistry 1988, 27, 3127-3129. [CrossRef]

27. Hwu, J.R.; Tseng, W.N.; Gnabre, J.; Giza, P.; Huang, R.C.C. Antiviral activities of methylated nordihydroguaiaretic acids. 1. Synthesis, structure identification, and inhibition of Tat-regulated HIV transactivation. J. Med. Chem. 1998, 41, $2994-3000$. [CrossRef] [PubMed]

28. Shimomura, H.; Sashida, Y.; Oohara, M. Lignans from Machilus thunbergii. Phytochemistry 1987, 26, 1513-1515. [CrossRef]

29. Lee, S.U.; Shim, K.S.; Ryu, S.Y.; Min, Y.K.; Kim, S.H. Machilin A isolated from Myristica fragrans stimulates osteoblast differentiation. Planta Med. 2009, 75, 152-157. [CrossRef]

30. Rochman, Y.; Kashyap, M.; Robinson, G.W.; Sakamoto, K.; Gomez-Rodriguez, J.; Wagner, K.U.; Leonard, W.J. Thymic stromal lymphopoietin-mediated STAT5 phosphorylation via kinases JAK1 and JAK2 reveals a key difference from IL-7-induced signaling. Proc. Natl. Acad. Sci. USA 2010, 107, 19455-19460. [CrossRef] [PubMed]

31. Song, J.W.; Seo, C.S.; Cho, E.S.; Kim, T.I.; Won, Y.S.; Kwon, H.J.; Son, J.K.; Son, H.Y. Meso-dihydroguaiaretic acid attenuates airway inflammation and mucus hypersecretion in an ovalbumin-induced murine model of asthma. Int. Immunopharmacol. 2016, 31, 239-247. [CrossRef] [PubMed] 